\title{
Non-Reacting Examination on Transverse Injection Upstream of Aft Wall Angled Cavities in an Axisymmetric Supersonic Flow
}

\author{
Shan M. Assis, S. Jeyakumar, K. Jayaraman
}

\begin{abstract}
Experiments on an air-fueled non-reacting scramjet test facility with four distinct aft wall angled cavity designs were performed in a Mach 1.8 flow field to explore the effects of transverse fuel injection system on scramjet combustors. Axisymmetric combustor cavity models were featured with two consecutive angles being inclined towards the downstream flow direction at the rear end. The wall mounted injector was located upstream from the cavity at a distance of 10 mm. Mixing performance within the various rear wall angled cavities were evaluated and compared with No-injection case for different injection pressures. Results revealed that the flow within the combustor was more uniform mixing compared to No-cavity configuration and was greatly influenced by injection pressures. Increase in injection pressures were characterized by enhanced mixing, greater stagnation pressure loss values and unstable flow.
\end{abstract}

Keywords : Transverse injection, Aft wall angled cavity, Scramjet combustor, Double angled cavity, wall static pressure.

\section{INTRODUCTION}

$S_{\text {cramjet engine technology continues to be the one with }}$ the most complex flow and reaction phenomena as the combustor efficiency is affected by many combined variables including the flow condition, the shape of the combustor and the fuel injection distribution. Integrated fuel injection/flame-holding methodology has been widely accepted by combustion scientists for optimization of the scramjet engine combustion process[1][2]. Fuel injection schemes and flame holding techniques plays a crucial role in the design and development of a supersonic combustion ramjet (scramjet) engine[3][2]. Cavity has been a widely adopted flame holding technique to increase residence time for mixing and chemical reactions[4]. Cavity flame holder, with an integrated fuel injection/flame-holding approach proposed for flame holding and stabilization in supersonic combustor, designed by CIAM (Central Institution of Aviation Motors) in Moscow, was used for the first time in a joint Russian/ French dual-mode scramjet flight-test[1][3].

Cavities plays a substantial role in keeping the combustor length relatively short compared to its diameter, while reducing the drag losses and thereby improving mixing characteristics[5].

Revised Manuscript Received on December 05, 2019.

* Correspondence Author

Shan M. Assis, Mechanical Engineering, Kalasalingam Academy of Research and Education, Tamil Nadu, India. Email: shanmassis@gmail.com
* S. Jeyakumar, Aeronautical Engineering, Kalasalingam Academy of Research and Education, Tamil Nadu-626126, India. Email: sjeyakumar1974@gmail.com

K. Jayaraman, Aerospace Engineering, Indian Institute of Technology Madras, Chennai-600008, India. Email: jayaraman78@gmail.com

Detailed study has been recommended by enormous scientist to explore the parametric design optimization pertaining to development of Integrated fuel injection/flame-holding system for improving the engine's combustion efficiency[6].

Finding a more reliable integrated fuel injection/flame-holding system is crucial for the development of scramjet combustor[2][7][4]. Flush wall mounted fuel injection methodology has been adopted by various scientists. It has been reported that bundle of bow shocks is formed in the front of the injector due to the obstruction from injection. This results in the separation of the upstream wall boundary creating a subsonic region where the boundary layer and jet fluids mix upstream of the injector base. Enhanced fuel air mixing is observed within these region and is depicted owing to the generation of counter-rotating vortices. Such an injection configuration at high velocities has been reported to have huge stagnation pressure losses due to the strong bow shock waves. The impact of the shock waves can be reduced by inclining injector angles and thereby stagnation pressure losses values can be reduced[8].

Stable flow fields within the integrated fuel injection/flame-holding system is crucial and can be controlled by stabilizing the shear layer which is largely influenced by the aspect ratios of the cavity geometry. Apart from the reduced cavity drag, strategically placed open cavity-based injection system has been reported with increased mixing enhancement and stable flameholding [9][10]. To optimize combustor performances, keeping the fuel injection location closer to the entrance has proved to be helpful[11]. Increasing the inclination of fuel injection and the injection pressures facilitates improved mixing characteristics in scramjet combustors. It has also been proved by the combustion scientists that flame stabilization is dependent on the location of the fuel injection and the flow stagnation temperature. Most of the open literatures reveals open cavity-based injection studies in two-dimensional combustors and studies in axisymmetric models are scant[12][13].

The aim of this study is to investigate the mixing performance of an upstream transverse injection within a rear wall double angled cavity in an axisymmetric supersonic field. In order to

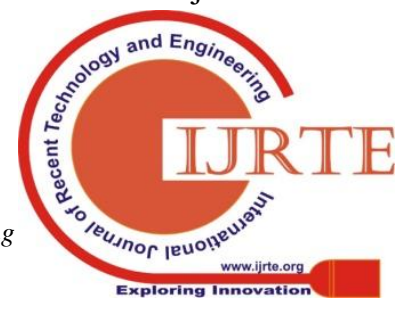


study the fuel mixing characteristics, air at different pressures were injected through a wall mounted injector located upstream from the cavity at a distance of $10 \mathrm{~mm}$.

Mixing performance within the various rear wall angled cavities were evaluated and compared with No-injection case for different injection pressures based on experimental investigation of static pressure distribution, momentum flux distribution and stagnation pressure loss. An additional objective was to determine flow stability conditions during upstream transverse injection within the aft wall angled cavities.

\section{TEST FACILITY SETUP}

The test facility comprising of a Reciprocating air compressor, Air storage tank, Air dryer, Ball valve, Control valve, CD nozzle, Isolator and the Supersonic combustor model as shown in figure 1(a) were used for the non-reacting flow experiments. An axisymmetric CD nozzle was adopted to supply a 1.8 Mach flow towards a $26 \mathrm{~mm}$ diameter and 95 $\mathrm{mm}$ long axisymmetric supersonic combustor. For the test, the flow's entry conditions were $0.38 \mathrm{MPa}$ stagnation pressure, $303 \mathrm{~K}$ stagnation temperature and $0.2 \mathrm{~kg} / \mathrm{s}$ flow rate. The schematic sectional view of Supersonic Combustor's scale down model with rear wall angled aft wall angled cavity is shown in Figure 1(b).

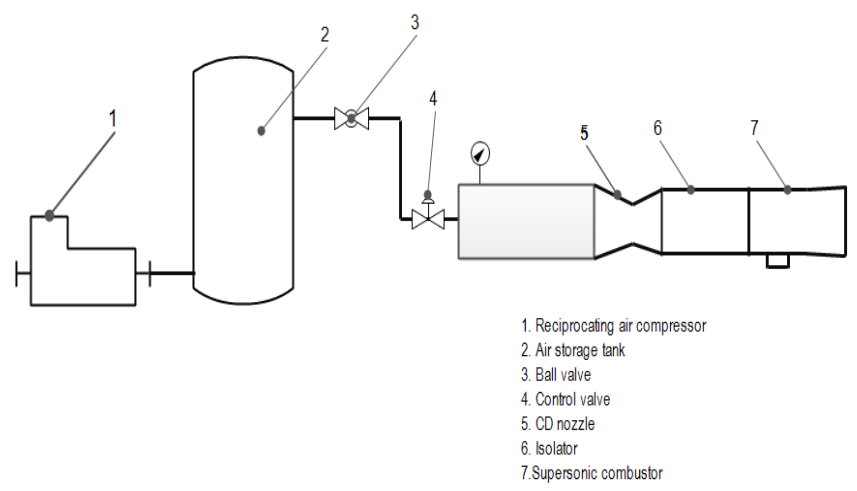

(a)

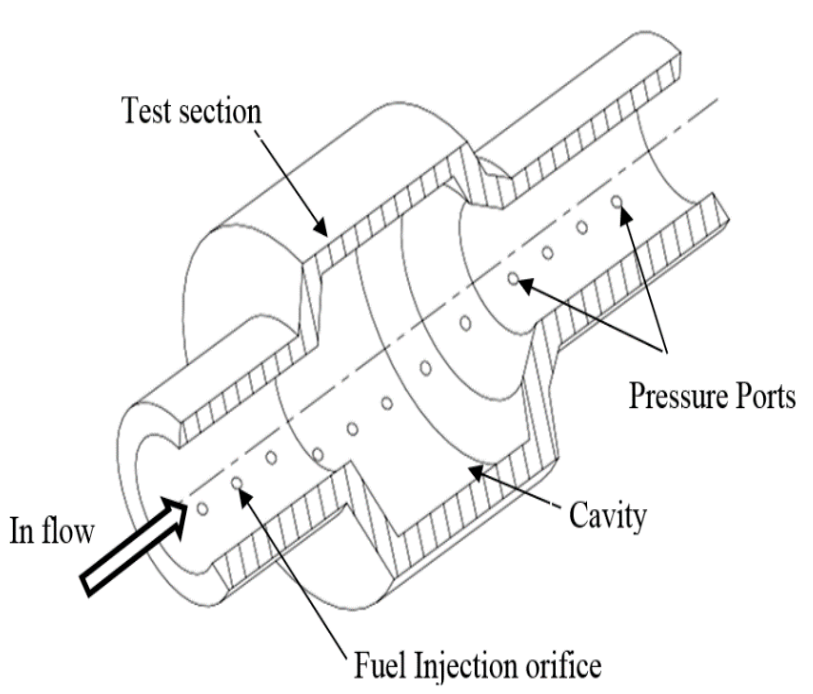

(b)
Fig. 1. (a) Experimental test facility setup layout and (b) Schematic sectional view of Supersonic Combustor with rear wall angled shaped cavity

For the open cavity-based injection experiments the cavities were located at a distance of $20 \mathrm{~mm}$ from the inlet. The aft wall angled-cavity chosen for this study was featured with varying double rear wall angled combination as shown in figure 2 . The cavity depth was kept constant about $10 \mathrm{~mm}$ and the effective length values varied as the geometry was changed and is depicted in the Table 1. A flush wall mounted transverse injector of $1 \mathrm{~mm}$ diameter was located at a distance of $10 \mathrm{~mm}$ upstream of the cavities. Air was injected through the transverse injector at different injection pressures of $0.6 \mathrm{MPa}, 0.65 \mathrm{MPa}$ and $0.7 \mathrm{MPa}$ respectively, to investigate the mixing performance and flow stability conditions of the aft wall angled cavity model. The mixing performance and flow stability characteristics were explored through the measurements of wall static pressure, momentum flux distribution and stagnation pressure loss parameters and by comparing with no-injection condition.

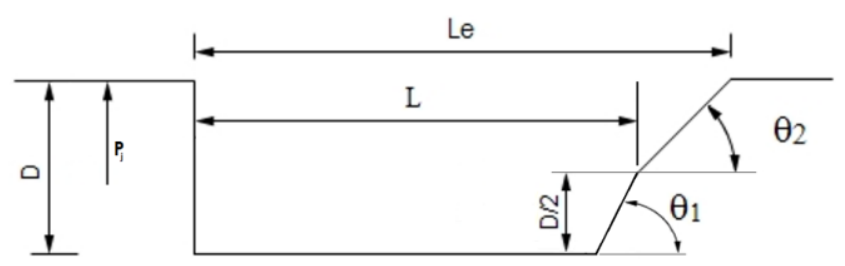

Fig. 2. Schematic of the Shaped-Cavity geometry along the axial plane

Table I. Geometrical Particulars Of Shaped Cavity Patterns

\begin{tabular}{|l|c|c|c|c|}
\hline $\begin{array}{c}\text { Cavity } \\
\text { Pattern }\end{array}$ & $\begin{array}{c}\text { Cavity } \\
\text { ratio } \\
(\mathrm{L} / \mathrm{D})\end{array}$ & $\begin{array}{c}\text { Effective } \\
\text { ratio } \\
(\mathrm{Le} / \mathrm{D})\end{array}$ & $\begin{array}{c}\text { Primary } \\
\text { Cavity } \\
\text { angle } \\
\left(\theta_{1}\right)\end{array}$ & $\begin{array}{c}\text { Secondary } \\
\text { Cavity } \\
\text { angle } \\
\left(\theta_{2}\right)\end{array}$ \\
\hline 90,90 & 4 & 4.0 & 90 & 90 \\
\hline 60,45 & 4.3 & 4.75 & 60 & 45 \\
\hline 60,30 & 4.3 & 5.1 & 60 & 30 \\
\hline 60,15 & 4.3 & 6.0 & 60 & 15 \\
\hline
\end{tabular}

Static pressure ports of $1 \mathrm{~mm}$ orifice diameter were located at carefully chosen axial locations at the bottom wall of the combustor model as represented in figure 1(b). A Scanning type pressure transducer (Scanivalve, Model: DSA3218, range: 0 to $1725 \mathrm{kPa}$, accuracy: $\pm 0.5 \%$ ) was used to evaluate the static pressure values and thereafter post processing was done in Labview program. Experiments were performed three times under similar working conditions to validate the repeatability of measurements. The uncertainty of the pressure measurements was evaluated to be less than $\pm 2 \%$. A combination of supersonic static and Pitot stagnation probes were used in the

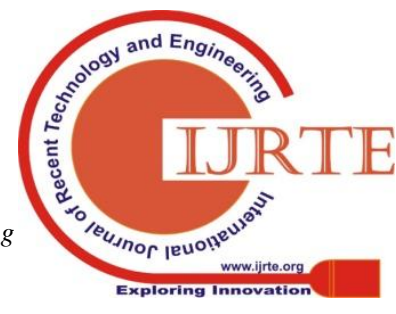


combustor exit plane to measure the radial pressure distribution values.

\section{RESULTS AND DISCUSSIONS}

\section{A. Wall Static Pressure Distribution}

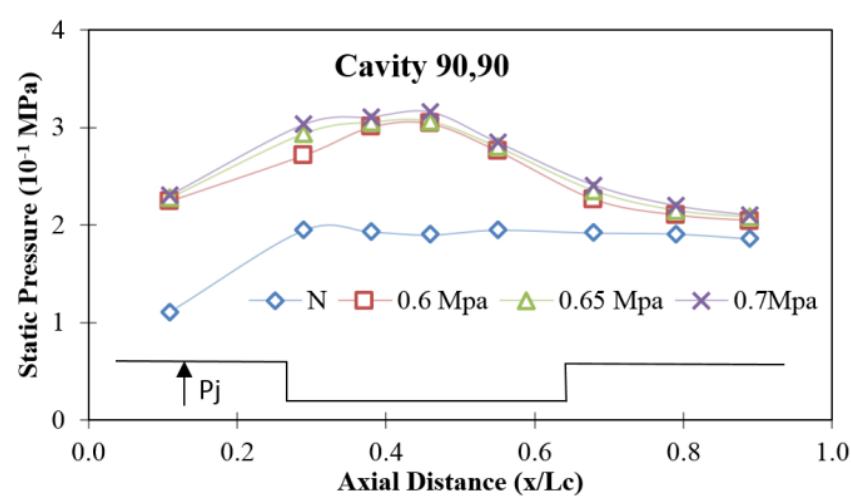

(a)

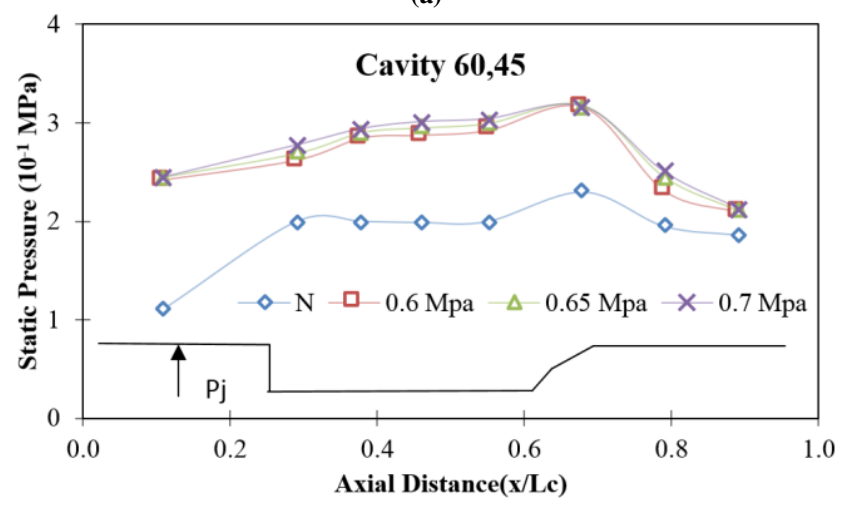

(b)

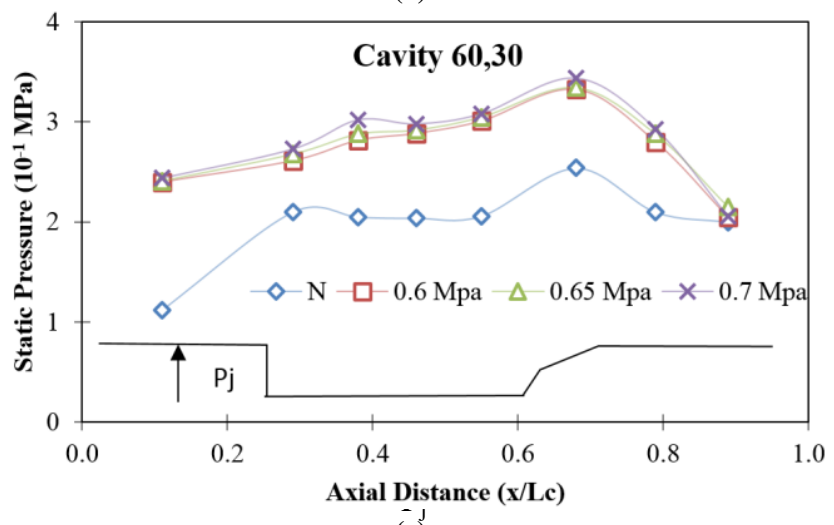

(c)

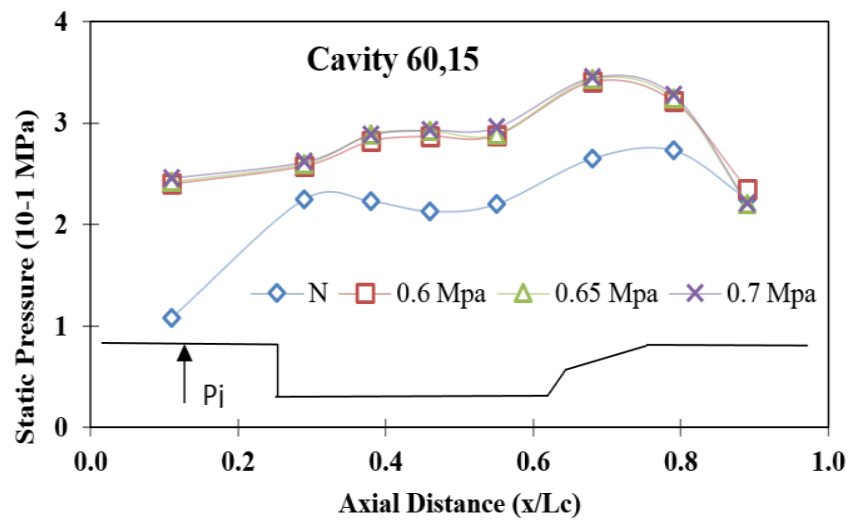

(d)
Fig. 3. Wall static pressure curves in the flow direction for different rear wall angled shaped cavities at various injection pressures.

The wall static pressure distribution in the flow direction measured at specific axial locations of the combustor for different rear wall angled aft wall angled cavities for 'No-injection' and simulated 'Injection' cases are shown in Figure 4. The axial distance from the the pressure port's from the combustor inlet ' $x$ ' is normalized by total length ' $L c$ ' and is shown in the abscissa, whereas the measured values of wall static pressure is shown in the ordinate. The curves are plotted for different fuel injection pressure conditions of 0.6 $\mathrm{MPa}, 0.65 \mathrm{MPa}$ and $0.7 \mathrm{MPa}$ and compared with 'No-injection' case which is represented as 'N'. The location of the fuel injection in the abscissa is at the distance of $\mathrm{x} / \mathrm{Lc}$ $=0.11$ from the combustor inlet (denoted as ' $\mathrm{p}_{\mathrm{j}}$ ' in the chart).

Flow over a rectangular cavity is generally influenced by the characteristics of the shear layer formed at the leading edge of the cavity which has direct influence on the flow stability and cavity drag parameters[14]. Higher static pressure values were observed at the leading edge of the cavity and is been due to the separation of the shear layer and its re-attachment at the rear wall, which results in the formation of a flapping motion and an unstable flow in the cavity region Figure 3(a) shows analogous profile for the flow over rectangular cavity $(90,90)$ during 'No-injection' case. Increase in injection pressure has been reported to cause heavy separation of the upstream boundary layer and enlarged cavity recirculation due to the interaction between the jet and the cavity shear layer[15]. Figure 3 (a to d) justifies the process of the upward lift of the shear layer during increase in injection pressure. In general for the 60 series aft wall angled cavities, when the secondary angles is reduced from 45 to 15 degrees, low values for static pressures were observed in the cavity region and its value increases at the rear wall and is depicted due to the shear layer reattachment at the rear wall angle $\left(\theta_{2}\right)$. As the static pressure profile remains similar irrespective of the variation in injection pressures, it is asserted that a stable flow filed is achieved for the different rear wall angled aft wall angled cavities. However the increase in static pressure values due the effect of injection pressures can lead to increased cavity drag[9]. The effect of the trailing edge shock over rear angles of these cavities can be minimized to a great extent with such aft wall angled cavity geometries as it make appropriate changes in length of cavity[3].

Maximum static pressure values are observed at the angled back wall region for all the 60 series cavities and is because of the shear layer reattachment and the edge shock waves developed due to the compressive zone. Highest values of wall static pressure were observed for the $(60,30)$ cavity, Figure 3c, at the trailing end of the angled cavity region. During transverse injection it is observed that the wall static pressure values starts

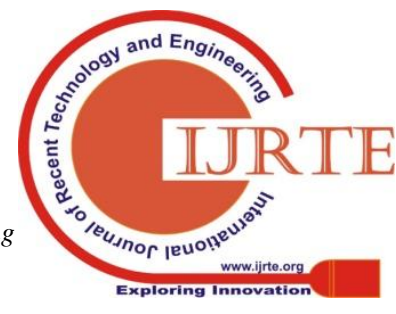


increasing at the leading edge due to the separation of the upstream wall boundary layer and creation of subsonic region at the vicinity of the injector.

The downstream static pressure profile for the 60 series cavities from the injector location follows analogous profile to the condition of 'No-injection'. Higher values of wall static pressure with respect to 'No-injection' case indicates increase in the entrainment flow rate into the cavity. Static pressure profile seems to be similar for both ' No-injection ' and ' Injection ' cases even the cavity rear wall angle $\left(\theta_{2}\right)$ to 30 degree (Figure 3c) and 15 degree (Figure 3d). More flow entrainment into the cavity is expected due the emergence of shock waves owing to jet interaction induced by cavity flush wall injection and due to the effect of the aft wall angled rear wall angled cavities.

\section{B. Momentum Flux distribution}

Mixing characteristics of flow within a scramjet combustor can be assessed by analysing the momentum flux profiles. Momentum flux distribution, $\mu$, values measured at the exit of the combustor in the radial direction gives direct indication on uniformity of mixing and is determined as

$$
\mu=\mathrm{p}\left(1+\gamma \mathrm{M}^{2}\right)
$$

where ' $p$ ' is the measured value of static pressure and Mach number ' $M$ ' is calculated from the measured values of static and stagnation pressures, using Rayleigh-Pitot formula.

For flows within axisymmetric cavities the momentum flux values at the center will be large and will reduces towards the wall indicating that the stagnation pressure at the center will be high than at the wall. A steady momentum flux profile along the radial direction at the exit of the combustor indicates uniform mixing. The momentum flux profile for the rectangular cavity $(90,90)$, Figure 4a, for both 'Injection' and 'No-injection' is not uniform showing poor mixing in the radial direction of the combustor. For the 60 series aft wall angled cavities with 'Injection', when the secondary angle is reduced from 45 to 15 degrees, the momentum flux values at the center decreases showing a more uniform profile. This can be depicted due to the generation of powerful shock waves produced by the jet supersonic cross-flow interaction in transverse injection schemes. This shock waves rises towards the center along the downstream flow and enhances the jet mixing. Thus increase in the fuel injection pressure results in increased penetration of the jet into the core stream. Unstable flow field over the cavity region for the rectangular cavity geometry, Figure $4 \mathrm{a}$, results in huge variation in the momentum flux values[14]. Almost an uniform profile is observed for the $(60,30)$, Figure $4 \mathrm{c}$, cavity than the other cavities within the 60 series. A fluctuating momentum profile observed for the $(60,45)$ and the $(60,15)$ cavities, Figure 4(b and d), at an axial distance of $\mathrm{x} / \mathrm{Lc}=0.62$ is due to the compressive zone formed at the rear walls due to the effect of aft wall angled cavity geometry. While considering the momentum flux profiles of all the aft wall angled cavities within the 60 series, almost a complete mixing showing uniform profile was observed for the 0.7
MPa injection pressure. It can also be asserted that increasing the fuel injection pressure can affect the stable flow field of the supersonic flow and hence affects uniform mixing. So it is always desirable to fix a proper fuel injection pressure based on the cavity geometry and the flow field to ensure uniform mixing. Future studies with reaction flow experiments helps to explore the effectiveness of mixing and combustion within a scramjet combustor.

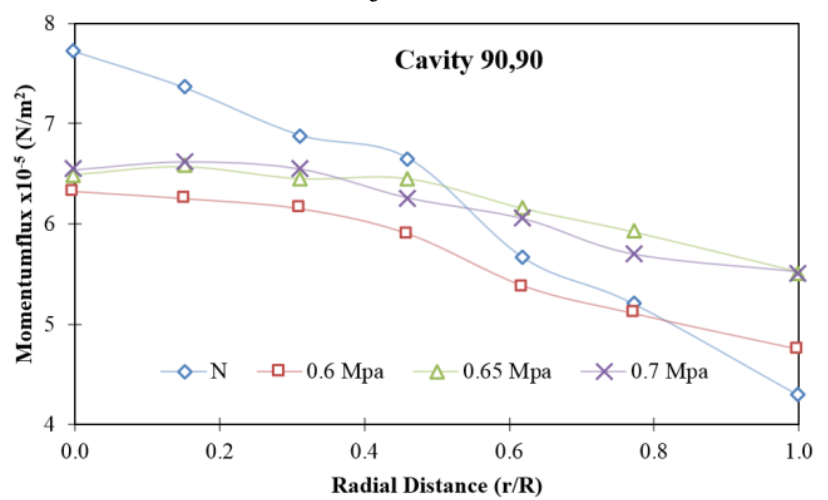

(a)

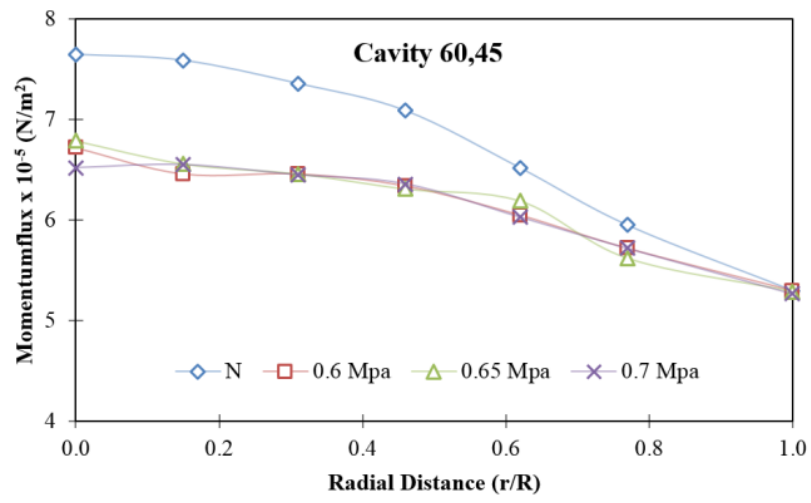

(b)

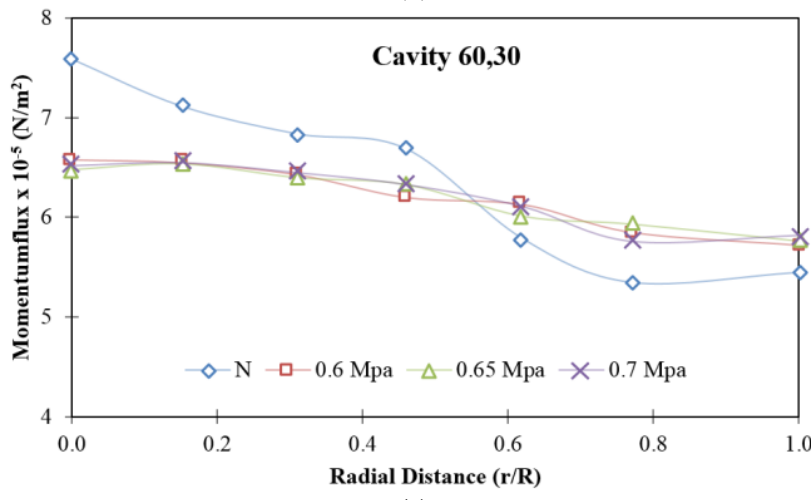

(c)

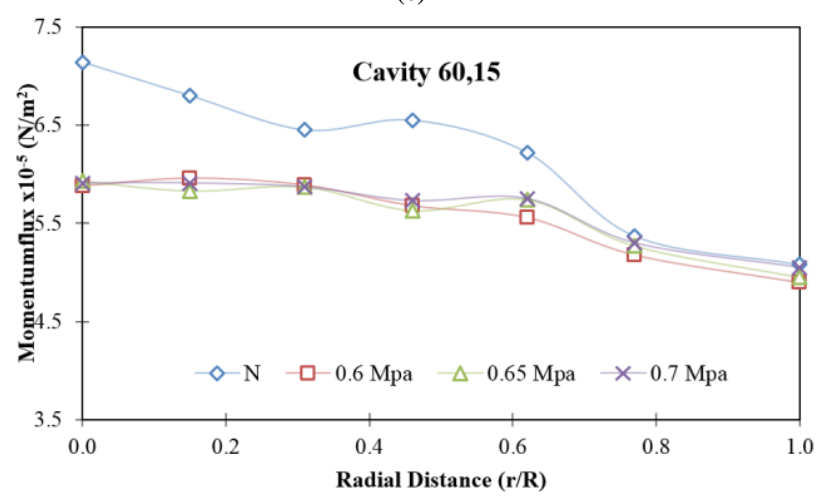

(d) 
Fig. 4. Momentum flux distribution in the radial direction for different rear wall angled shaped cavities at various injection pressures

\section{Stagnation Pressure Loss}

The difference in stagnation pressure values measured at the inlet and the axial distance considered to the inlet stagnation pressure of the combustor gives the stagnation pressure loss value across the supersonic combustor. Figure 5 shows the stagnation pressure loss curves for 'No-injection' and 'Injection' conditions for different rear wall angled aft wall angled cavities. Considering the 'Injection' condition, irrespective of the cavity geometry, it is clear that increase in injection pressure will increase the stagnation pressure loss value. It is assessed due to generation of huge three-dimensional bow shock as the jet interacts with the core stream and the resulting unstable flow field caused by higher injection pressures. It is also reported that increase in stagnation pressure loss is caused by deep penetration of injectant jet into the core flow. Depending on the shock waves intensity emerging from the leading and trailing edges of the aft wall angled cavity, the stagnation pressure loss values decrease when the rear wall angle is lowered. Suitable selection of injection pressure and the aft wall angled cavity geometry can optimize the stagnation pressure loss values thereby ensuring more combustion efficiency.

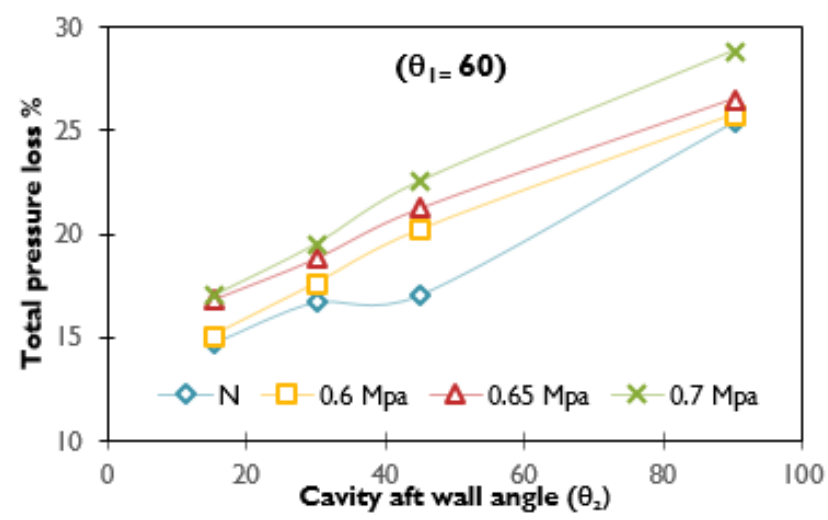

Fig. 5. Stagnation pressure loss curves for different rear wall angled shaped cavities at various injection pressures.

\section{CONCLUSIONS}

In a non-reacting Mach 1.8 flow, the transverse upstream injection of an axisymmetric rear wall angled aft wall angled cavity is investigated experimentally. The mixing performance and flow stability characteristics were explored through the measurements of wall static pressure, momentum flux distribution and stagnation pressure loss parameters and by comparing with no-injection condition.

1) Increase in injection pressure causes upward lift of the upstream boundary layer and formation of enlarged cavity recirculation due to the interaction between the jet and the cavity shear layer.
2) Increasing the fuel injection pressure can affect the stable flow field of the supersonic flow and hence affects uniform mixing.

3) Irrespective of the cavity geometry, increase in injection pressure will increase the stagnation pressure loss value due to generation of huge three-dimensional bow shock as the jet interacts with the core stream and the results in unstable flow.

4) Suitable selection of injection pressure and the aft wall angled cavity geometry can optimize the stagnation pressure loss values, leading to stable flow field and enhanced mixing, thereby ensuring improved combustion efficiency.

\section{ACKNOWLEDGMENT}

This work is supported by Department of Science and Technology under the Grant No: SR/FTP/ETA-55.

\section{DISCLOSURE STATEMENT}

No potential conflict of interest was reported by the authors.

\section{NOMENCLATURE}

L Length of the cavity ( $\mathrm{mm})$

D Depth of the cavity (mm)

$\theta \quad$ Rear wall angle (deg)

$\mu \quad$ Momentum flux $\left(\mathrm{N} / \mathrm{m}^{2}\right)$

$\mathrm{p}$ Static pressure $\left(\mathrm{N} / \mathrm{m}^{2}\right)$

$\mathrm{p}_{\mathrm{o}} \quad$ Stagnation pressure $\left(\mathrm{N} / \mathrm{m}^{2}\right)$

M Mach number

$\mathrm{R}$ Radius of the combustor (mm)

$\mathrm{r}$ Incremental radial distance (mm)

$\mathrm{X}$ Incremental axial distance ( $\mathrm{mm})$

$\gamma \quad$ Specific heat ratio

Subscripts

1 Primary angle

2 Secondary angle.

\section{REFERENCES}

1. J. V. S. Moorthy, B. Rajinikanth, and B. V. N. Charyulu, "Effect of ramp-cavity on hydrogen fueled scramjet combustor," Propuls. Power Res., vol. 3, no. 1, pp. 22-28, 2014.

2. G. Yu, J. G. Li, X. Y. Chang, and L. H. Chen, "Fuel Injection and Flame Stabilization in a Introduction," vol. 19, no. 5, 2003.

3. K. M. Kim, S. W. Baek, and C. Y. Han, "Numerical study on supersonic combustion with cavity-based fuel injection," vol. 47, pp. 271-286, 2004.

4. Y. Pan, J. T. J. Liang, and W. L. Z. Wang, "Experimental investigation of combustion mechanisms of kerosene-fueled scramjet engines with double-cavity flameholders," vol. 27, pp. 891-897, 2011.

5. R. Burnes, T. P. Parr, K. J. Wilson, A. Asme, S. A. E. Asee, and J. Propulsion,

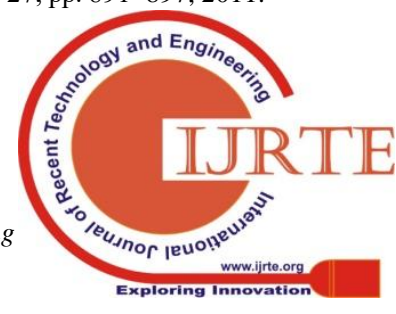


"Investigation of Supersonic Mixing Control Using Cavities : effect of fuel injection location,” AIAA Pap. 2000-3618, no. July, 2000.

6. S. L. Gai, H. Kleine, and A. J. Neely, "Supersonic Flow over a Shallow Open Rectangular Cavity,” J. Aircr., vol. 52, no. 2, pp. 609-616, 2015.

7. T. Mathur et al., "Supersonic Combustion Experiments With a CavityBased Fuel Injector Air Force Materiel Command," 2006.

8. A. Ben-Yakar and R. K. Hanson, "Cavity Flame-Holders for Ignition and Flame Stabilization in Scramjets: An Overview," Journal of Propulsion and Power, vol. 17, no. 4. pp. 869-877, 2008.

9. A. Ben-Yakar and R. K. Hanson, "Cavity Flame-Holders for Ignition and Flame Stabilization in Scramjets: An Overview," J. Propuls. Power, vol. 17, no. 4, pp. 869-877, 2001.

10. K. H. Yu, K. J. Wilson, and K. C. Schadow, "Effect of Flame-Holding Cavities on Supersonic-Combustion Performance," J. Propuls. Power, vol. 17, no. 6, pp. 1287-1295, 2001

11. W. Xianyu, L. Xiaoshan, D. Meng, L. Weidong, and W. Zhenguo, "Experimental Study on Effects of Fuel Injection on Scramjet Combustor Performance," vol. 20, pp. 488-494, 2007.

12. S. Jeyakumar, S. M. Assis, and K. Jayaraman, "Experimental study on the characteristics of axisymmetric cavity actuated supersonic flow," Proc. Inst. Mech. Eng. Part G J. Aerosp. Eng., vol. 231, no. 14, 2017.

13. S. Jeyakumar, S. M. Assis, and K. Jayaraman, "Effect of Axisymmetric Aft Wall Angle Cavity in Supersonic Flow Field," Int. J. Turbo Jet Engines, vol. 35, no. 1, 2018.

14. S. Jeyakumar, S. M. Assis, and K. Jayaraman, "Experimental study on the characteristics of axisymmetric cavity actuated supersonic flow," Proc. Inst. Mech. Eng. Part G J. Aerosp. Eng., vol. 231, no. 14, pp. 2570-2577, 2017.

15. H. Wang, Z. Wang, M. Sun, and N. Qin, "Combustion characteristics in a supersonic combustor with hydrogen injection upstream of cavity flameholder,” Proc. Combust. Inst., vol. 34, no. 2, pp. 2073-2082, 2013.

\section{AUTHORS PROFILE}

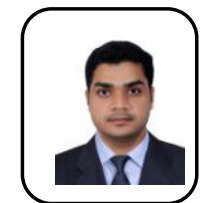

Shan M. Assis is a post graduate in Mechanical engineering and currently a PhD Research Scholar at Kalasalingam Academy of Research and Education, Tamil Nadu, India. His research interest areas are on Supersonic Combustion, Refrigeration \& Heat Transfer applications and Flow simulation studies.

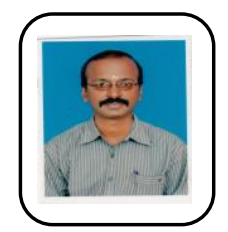

Dr. S. Jeyakumar working as Professor in Aeronautical Engineering, Kalasalingam Academy of Research and Education. The author has published papers in the areas of high-speed flow mixing and combustion, cavity flow, dual combustion ramjet engine.

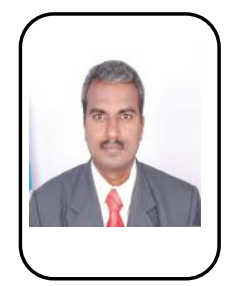

Prof. Dr. K. Jayaraman is presently working as Principal Scientist at Department of Aerospace Engineering, IIT Madras, Chennai He was awarded for Sandwich Postdoc Fellowship from Science Technology and Service, Embassy of France, New Delhi, India. He research areas are solid propellants, renewable energy technology; the pyrolysis, combustion and gasification studies of several carbonaceous materials, 